\title{
Photovoltaic Assemblies For The Power Generation Of The Exomars Missions
}

\author{
Emanuele Ferrando(1), Pietro Zanella(1), Stefano Riva(1), Giulia Damonte(1), Romano Romani ${ }^{(1)}$, Luigi Ferrante ${ }^{(1)}$ \\ (1) Leonardo SpA, Viale Europa snc, Nerviano (MI), \\ Email: emanuele.ferrando@leonardocompany.com,pietro.zanella@leonardocompany.com, \\ stefano.riva01@leonardocompany.com,giulia.damonte@leonardocompany.com, \\ romano.romani@leonardocompany.com,luigi.ferrante@leonardocompany.com
}

\begin{abstract}
This paper provides a detailed description of the Photovoltaic Assembly (PVA) and, in particular, how the extreme environmental and operative requirements of the Exomars missions are met. "Exomars" is a program established by the European Space Agency to investigate the Martian environment and to validate new technologies in view of future Mars exploration missions. The first mission will be launched in 2016 and will carry a spacecraft composed of the Trace Gas Orbiter (TGO) and the Entry, descent and landing Demonstrator Module (EDM). The second mission is scheduled on year 2018 and will carry a rover vehicle. Leonardo PVA contribution is on either the TGO, Carrier and Rover vehicle solar arrays. Moreover we were deeply involved in the design of the power conditioning and distribution electronics of the TGO leveraging on our Power Management and Distribution heritage for scientific platforms.
\end{abstract}

As far as Exomars SA's (Solar Array) are concerned, they are significantly different: the TGO is based on two deployable wing system, whose attitude is controlled by the SADM. Each wing comprehends two panels.

The Rover vehicle solar array assembly (SAA) is made of a fixed panel and four deployable (primary and secondary) panels. This SAA is unique with respect to standard deployable systems because of the motor deployment control and trimming possibilities during Martian soil exploration.

Each of these missions imposed major design challenges: for the TGO the aero braking maneuvers will cause a significant dissipation of the kinetic energy leading to a solar array temperature increase up to $+175^{\circ} \mathrm{C}$ on the rear face, while $+135^{\circ} \mathrm{C}$ on the front (active) face. On the other hand, during the cruise phase the same PVA will experience extreme cold temperatures down to $-209^{\circ} \mathrm{C}$.

For the rover SAA the biggest challenge is related to surviving Mars planet environment (i.e. dust, wind and charge accumulation) and the associated mechanical and electrical constraints. We duly considered the experience gained by NASA-JPL on previous Mars lander missions and the selected technical solutions, all taken from the European heritage, represent the evolution to what already successfully flown.

Finally the bio burden and planetary protection requirements are also not a standard in SA field. A special manufacturing, assembly and test sequence will be implemented to capitalize our previous experience on the Mars drill tool development. For both the arrays European PVA technology was exclusively used: more specifically high efficiency III-V compounds solar cells and a new glass grounding network.

\section{PVA technology for MARS missions}

The Photovoltaic Assembly is part of the solar array, which design is driven by the complexity of the various missions to Mars. Different solutions has been implemented depending on the specific missions.

\subsection{Exomars TGO PVA}

On the Exomars TGO the aero braking sequence will be the most demanding phase. The aero braking manoeuvre will be performed near Mars. It is aimed to reduce the orbital period via about several passes through the upper level of the Mars atmosphere. The kinetic energy of the spacecraft that will be dissipated to get the necessary delta- $\mathrm{V}$ will cause a solar array temperature increase up to $+175^{\circ} \mathrm{C}$ on the rear face, so mainly affecting discrete EEE parts and wiring, while $+135^{\circ} \mathrm{C}$ on the front face, so for the solar cells and bypass diodes.

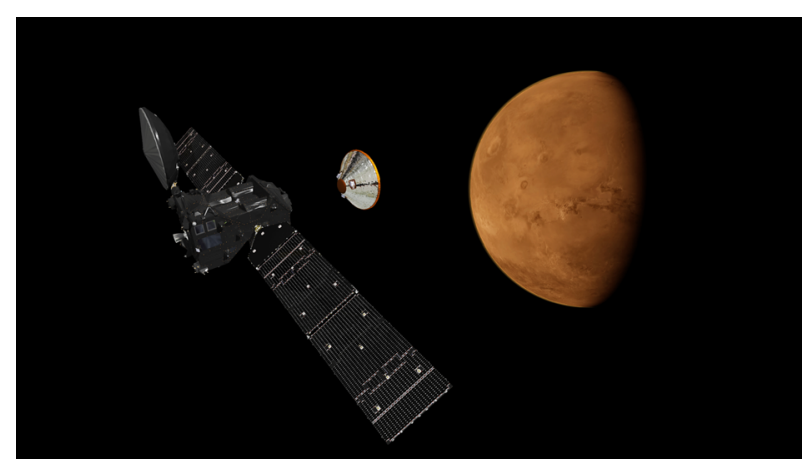

Figure 1. EXM TGO artistic view (courtesy of ESA).

SA is composed of two deployable wings, each one made of two identical panels and one Solar Array Drive Mechanism (SADM). Each panel has an electrical network consisting of 10 electrical sections with $6 / 7$ strings each, for a global 65 parallel $\times 22$ series configuration. Each string is protected by 2 blocking diodes grouped at section level into a single diode board. As distance between panel is very low during 
stowed phase $(8 \mathrm{~mm})$, the rear side layout has been routed in a specific way to avoid any overlapping between elements while keeping a common unique configuration.

The AZUR space $3 \mathrm{G} 28$ is the selected solar cell baseline in combination with an external $\mathrm{Si}$ planar bypass diode (SIBPD). These two items followed an almost independent manufacturing process flow and are integrated one to each other at string formation level.

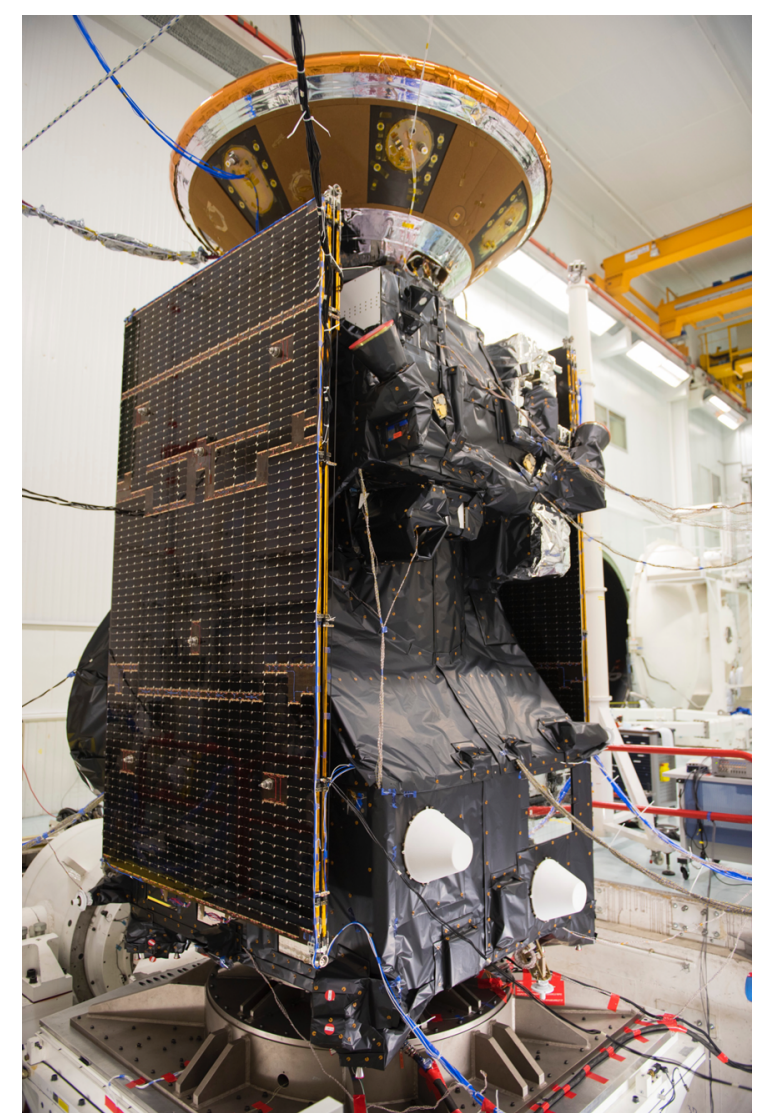

Figure 2. EXM TGO satellite during vibrational test (courtesy of ESA).

Table 1. EXM TGO PVA main characteristics.

\begin{tabular}{|l|l|}
\hline $\begin{array}{l}\text { Solar cell } \\
\text { Assembly }\end{array}$ & $\begin{array}{l}\text { AZUR Space 3G 28\% GaAs/Ge solar cell } \\
\text { Dow Corning DC93500 adhesive } \\
\text { CMG QioptiQ Coverglasses }\end{array}$ \\
\hline $\begin{array}{l}\text { Protection } \\
\text { diode }\end{array}$ & $\begin{array}{l}\text { AZUR Space SIBD silicon diode } \\
\text { Dow Corning DC93500 adhesive } \\
\text { QioptiQ CMG Coverglasses }\end{array}$ \\
\hline $\begin{array}{l}\text { PVA } \\
\text { layout }\end{array}$ & $\begin{array}{l}\text { 2 wings of 2 panels each } \\
1 \text { panel with 10 section of } 6 / 7 \text { strings each } \\
65 \text { strings (22 cells each) per panel } \\
\text { (5720 solar cells) }\end{array}$ \\
\hline $\begin{array}{l}\text { Installed } \\
\text { Power }\end{array}$ & $\begin{array}{l}- \text { Begin Of Life } \\
-1 \text { solar constant, AM0, 28 }{ }^{\circ} \mathrm{C} \\
- \text { Max available Power @ SA: 6360 W }\end{array}$ \\
\hline
\end{tabular}

\subsection{Exomars Rover PVA}

Exomars Rover Vehicle solar array is a unique equipment, different from anything else developed before in Europe. No off the shelf solution are readily available on the market. The biggest challenge in terms of development and qualification efforts is related to surviving Mars planet environment (i.e. dust and wind) and the associated mechanical and electrical constraints. Due to the above, the experience gained by the Americans on previous Mars lander missions was duly considered and the selected technical solutions are in continuity with respect to what already successfully flown.

The solar array will be released and deployed following landing, prior to the commencement of surface operations.

For maintaining mission operation flexibility, the solar array may be partially deployed (primary panels only) or fully deployed (primary \& secondary panels) whilst on the Lander Platform.

Prior to egress, the Rover remains connected to the Lander Platform via electrical umbilical's. Solar array deployment is completed after the Rover has egressed onto the surface (if not fully deployed on the Lander Platform).

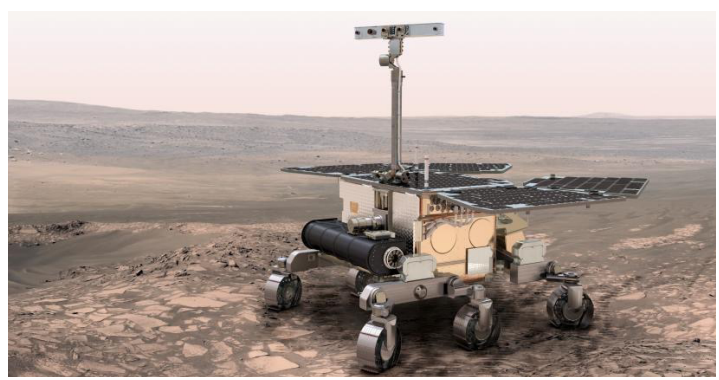

Figure 3. EXM Rover vehicle (courtesy of ESA).

During egress and mobile operations the deployed solar array will be latched into its nominal deployed configuration and exposed to mechanical loading arising from the rough terrain. The Rover will only drive during daylight and will be stationary at the end and beginning of each sol. During these stationary periods, the angles of the deployable panels will be adjusted by rotation about the primary hinges to increase the incident solar energy.

The need for the mechanisms to operate in the Mars atmosphere imposes extra requirements with respect to typical space projects, where operation is normally in vacuum. In particular, the presence of dust in the Mars atmosphere could contaminate the mechanisms affecting their functionality. These constraints could affect the SAA mechanisms, although no tests in such Martian environment are foreseen for the SAA mechanisms.

The solar array assembly comprises the following parts:

- Fixed SA panel with PVA and wiring harness

- Primary deployable SA panels with PVA and wiring harness 
- Secondary deployable SA panels with PVA and wiring harness.

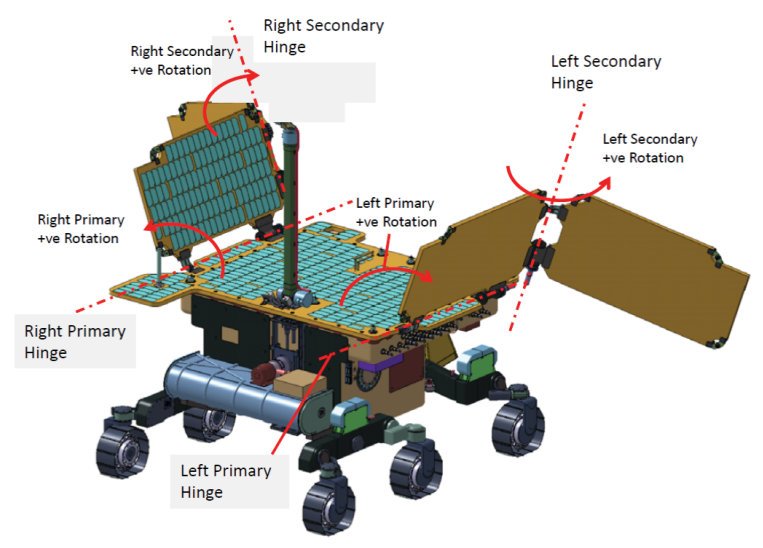

Figure 4. EXM Rover vehicle deployment (courtesy of Airbus).

For what concerns the electrical parts (PVA and wiring harness) the following parts are considered:

- Solar cell assemblies, string blocking diodes, thermistors and bleed resistors

- Electrical harness to bulkhead connectors

- Electrical harness to ADE for deployment lines

The selected solar cell is the AZUR Space $3 \mathrm{G} 30$ with an external $\mathrm{Si}$ by pass diode. A specific requirement on the glass grounding network.

It is mandatory to create a common ground network for all the glass exposed surfaces. This means the use of Indium Tin Oxide (ITO) coating on top of the glass surface and a stable connection of this coating to the PVA network.

To do so a specific glass was selected with antireflective coating on top of ITO coating. Moreover the glass layout is such that the cell and the by-pass diode are covered by the same glass. With the above solution the grounding of the ITO is done via the by-pass diode top contact, partly exposed. A drop of Silicone conductive adhesive is the connection in between the glass edge conductive coating and the reference network point.

Table 2. EXM Rover PVA main characteristics.

\begin{tabular}{|l|l|}
\hline $\begin{array}{l}\text { Solar cell } \\
\text { Assembly } \\
\text { (including } \\
\text { protection } \\
\text { diode) }\end{array}$ & $\begin{array}{l}\text { AZUR Space 3G 30\% GaAs/Ge solar cell } \\
\text { AZUR Space SIBD silicon diode } \\
\text { Dow Corning DC93500 adhesive } \\
\text { QioptiQ CMG ITO unique Coverglasses } \\
\text { Nusil CV3-2640 conductive adhesive }\end{array}$ \\
\hline $\begin{array}{l}\text { PVA } \\
\text { layout }\end{array}$ & $\begin{array}{l}40 \text { strings of } 18 \text { cells each. Divided into } \\
-\quad \begin{array}{l}\text { sections with } 6 \text { strings each } \\
\text { (deployable panels) }\end{array} \\
-\begin{array}{l}2 \text { sections with } 8 \text { strings each } \\
\text { (central panel) } \\
(720 \text { solar cells in total) }\end{array}\end{array}$ \\
\hline
\end{tabular}

\begin{tabular}{|l|l|}
\hline Installed & - Begin Of Life \\
Power & -1 solar constant, AM0, 28 ${ }^{\circ} \mathrm{C}$ \\
& - Max available Power@ SA: 828 W \\
\hline
\end{tabular}

\subsection{Exomars Carrier PVA}

The Exomars Carrier is by sure the less demanding mission amongst the ones here described. Based on that the proposed PVA is the evolution of EXM TGO solutions.

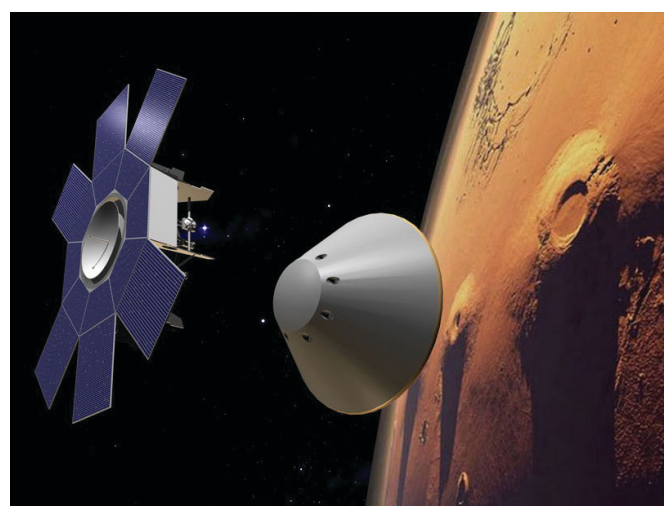

Figure 5. EXM Rover vehicle deployment (courtesy of Airbus).

SA is composed by 8 base panels (body mounted), surrounded by 6 deployable panels. The rear side of the panels is thermally shielded with a Multi Layer Insulator (MLI).

The most important characteristic of this solar array is the relatively complex panel layout and distribution and the extremely limited number of fatigue cycles to whom the PVA will be subjected.
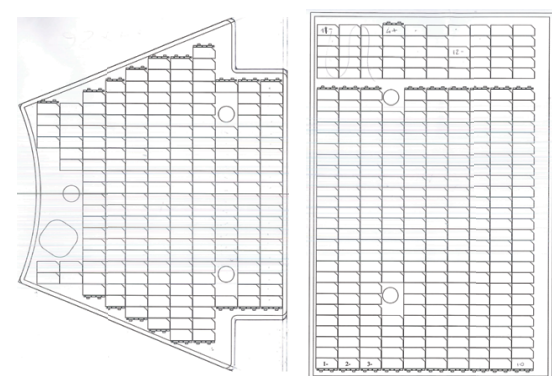

Figure 6. EXM Carrier panel.

Base panel layout (left), deployable panel (rigth)

The presence of MLI impose the double insulation on each of the rear side electrical components. This is performed using conformal coating on exposed surfaces and kapton insulation patches.

Some improvements has been selected regarding the rear side integration technology. One of them is related to the usage of bi-adhesive layer between for fiberglass board of EEE parts, instead of RTV adhesive. 
The selected solar cell is the Azur space 3G30 in combination to the Azur SIBD silicon protection diode.

Table 3. EXM TGO PVA main characteristics.

\begin{tabular}{|l|l|}
\hline $\begin{array}{l}\text { Solar cell } \\
\text { Assembly }\end{array}$ & $\begin{array}{l}\text { AZUR Space 3G 30\% GaAs/Ge solar cell } \\
\text { Dow Corning DC93500 adhesive } \\
\text { CMG QioptiQ Coverglasses }\end{array}$ \\
\hline $\begin{array}{l}\text { Protection } \\
\text { diode }\end{array}$ & $\begin{array}{l}\text { AZUR Space SIBD silicon diode } \\
\text { Dow Corning DC93500 adhesive } \\
\text { QioptiQ CMG Coverglasses }\end{array}$ \\
\hline $\begin{array}{l}\text { PVA } \\
\text { layout }\end{array}$ & $\begin{array}{l}\text { 6 base panels with 9 strings } \\
6 \text { base "modified" panels with 8 strings } \\
6 \text { deployable panels with 11 strings } \\
\text { All the strings with 26 cells each } \\
1 \text { section per panel } \\
\text { (3536 solar cells) }\end{array}$ \\
\hline $\begin{array}{l}\text { Installed } \\
\text { Power }\end{array}$ & $\begin{array}{l}- \text { Begin Of Life } \\
-1 \text { solar constant, AM0, 28 }{ }^{\circ} \mathrm{C} \\
- \text { Max available Power } @ \text { SA: } 4084 \mathrm{~W}\end{array}$ \\
\hline
\end{tabular}

\section{Qualification}

As a general approach the PVA qualification have been achieved at two levels: solar cell assembly and coupon assembly. Several tests have been already performed at solar cell assembly level so the final adaptation to the specific project requirements is accomplished by means of a delta Type Approval Test (TAT) according to European Standard guidelines while the second by means of Design Verification Test (DVT) coupons.

\subsection{Solar Cell Assembly qualification}

Leonardo heritage comprehends a full qualification performed in accordance to relevant ECSS for solar cell assembly base on Azur 3G28 triple junction (EXM TGO configuration) and more recently Azur 3G30.

Delta TAT has been defined in order to cover the different project environment involving assemblies based on 3G30 either on EXM Carrier either on EXM Rover.

The Delta TAT are focused on the differences with respect to standard PVA with a consistent qualification and flight heritage. More precisely great attention was given to:

- ESD grounding network and conductive glass stability

- External Si diode assembly

- Characterization of the solar cells against different Mars light conditions

- $\quad$ Long term storage at SCA level

\subsection{DVT qualification}

The purpose of DVT qualification is to demonstrate that the whole PVA technology is suitable to withstand the whole stresses induced by the mission environment, including qualification and design margins.

The same coupon dimension $(420 \times 440 \mathrm{~mm} 2)$ has been adopted for all projects.
Table 4. EXM TGO PVA main characteristics.

\begin{tabular}{|l|l|}
\hline EXM TGO & 2 strings with 22 cells each \\
\hline EXM Carrier & 2 strings with 22 cells each \\
\hline EXM Rover & 2 strings with 18 cells each \\
\hline
\end{tabular}

The DVTs are manufactured using the same materials, mechanical parts, components and processes that are used for the FM panels.

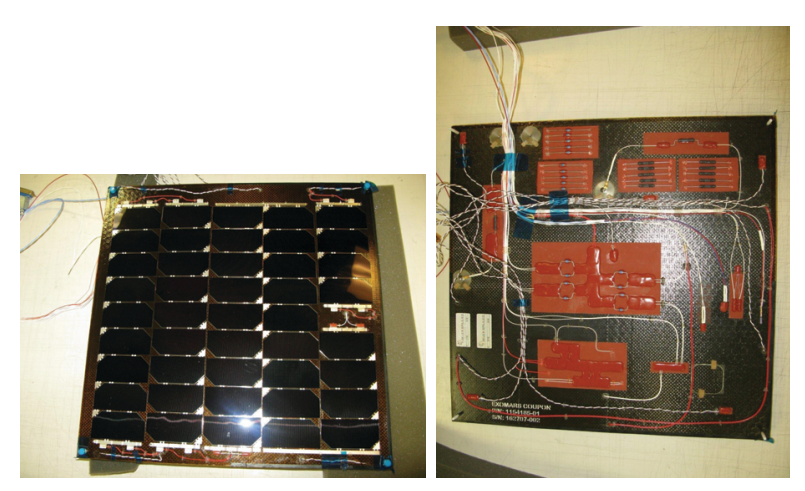

Figure 7. EXM TGO DVT coupon

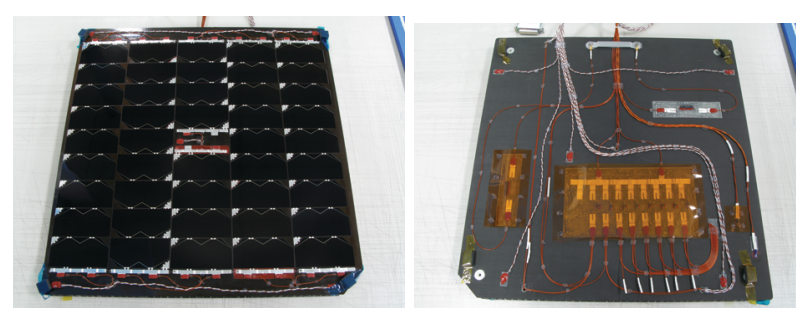

Figure 7. EXM Carrier DVT coupon

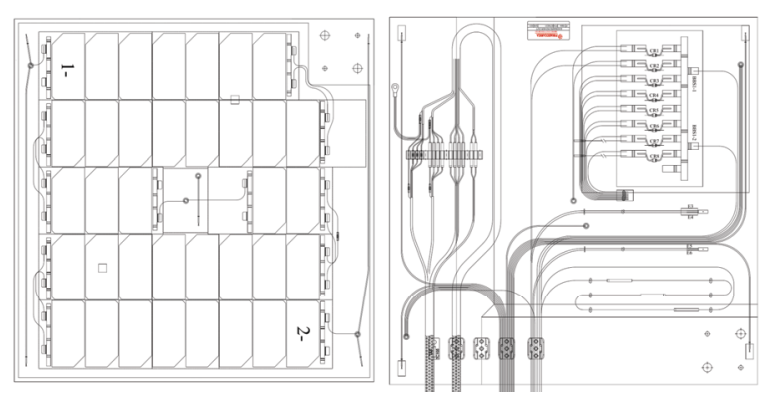

Figure 7. EXM Carrier DVT coupon

The qualification coupons will be submitted to a complete environmental test campaign consisting in:

- Thermal vacuum baking and cycling

- Accelerated ambient pressure fatigue cycles.

Moreover for the EXM Rover sample, specific test are foreseen

- Corona test

- Exposure to Mars wind and dust environment 


\subsection{STM/EM/QM models}

No additional qualification models are foreseen except for the Rover that will foresee an STM, an EM and a QM models.

The STM will be structurally and thermally representative of the equipment in terms of mass distribution, stiffness of primary load parts, thermal control and mechanical and thermal interfaces. Actuator functionality is not required though it shall be manually reconfigurable to the stowed and deployed conditions.

The STM shall be subject to qualification level mechanical test. No thermal tests are foreseen at SAA level and they can be performed after the integration together with the rest of the Rover module.

The PVA STM will be integrated on panel substrates. The result of the integration will be one set of STM panels (fixed panel, primary deployable left panel, secondary deployable left panel, primary deployable right panel, secondary deployable right panel), populated with mass dummies.

Front side thermo-optical representativeness will be achieved using black anodized Al plates of approximately the same size of solar cell assemblies.

The Mechanisms STM will be structurally and thermally representative of the equipment in terms of mass distribution, stiffness of primary load paths, thermal control and mechanical and thermal interfaces. No actuator functionality will be provided, but it will be possible to manually configure the model to the stowed and deployed conditions. Before delivery, the model will be submitted to vibration and thermal tests, in order to reproduce the specified mechanical environment at qualification level and correlate the thermal model. At SAA level, the model will allow verification of the structural and thermal characteristics of the proposed design.

A QM model shall be subject to the full equipment level qualification test sequence and environment, including adequate qualification levels, duration, and margins as agreed by the customer. This shall include life test when it is required to be demonstrated.

Following its successful qualification test sequence, a QM model shall not be acceptable for flight, unless otherwise agreed.

Nevertheless it is Selex opinion that the QM panels, properly refurbished can be considered as FM spares in case of needs.

All mechanisms shall be qualified using a QM. The Statement of Work requires a QM of the full Solar Array Assembly.

Its two sub-assemblies, namely the PVA and the mechanisms will undergo a qualification campaign on their respective QM. Then, integrated tests at QM level will also be performed.

A proper splitting between stand-alone and integrated tests is proposed, described in the test plan, in order to optimise the effectiveness of the test campaign and the associated schedule.

The QM will be submitted to the same test sequence as per FM with the only difference of the testing levels that in this case will be aligned to the wider qualification range rather to be reduced to the acceptance levels.

The Mechanisms QM will be built to the full flight standard. Before testing, it will be submitted to TBD (one-to-three) cycles of dry heat microbial reduction (DHMR), in order to prove compatibility with this process. It will be subject then to the specified qualification test sequence and environment. After the environmental testing, the model (or the relevant parts of it: the mechanisms) will be subject to life testing in order to complete its verification. Then, the model will be integrated into the SAA QM for assembly level qualification activities.

The SAA QM will be subject to the qualification campaign. At the end, a bake-out in $\mathrm{T} / \mathrm{V}$ chamber is foreseen which covers also DHMR aspects.

The QM will comply with planetary Protection and cleanliness requirements and procedures. The QM is to be used to trial run PP practices in readiness for FM campaign. A bio-burden budget will be assigned to the FM based on the exposed and encapsulated surface area of the subsystem.

\section{Qualification results}

Qualification at component level has been successfully achieved at solar cell assembly level, finalizing the $3 \mathrm{G} 28$ and $3 \mathrm{G} 30$ full coverage as per PVA ECSS of the Exomars mission.

Specific test are foreseen to cover the ITO coating network that are to be completed.

DVT campaign is successfully completed for EXM TGO, while it is running on EXM carrier and to be started on EXM rover.

Expected end of qualification for EXM carrier is foreseen by end of 2016, while during 2017 for EXM Rover.

\section{Conclusion}

Leonardo is proud of the PVA technology developed so far for the various Exomars programs in which there was our direct involvement.

Several solutions implemented for complying with program specific requirements can be proposed on a variety of space missions to near Earth or Interplanetary orbit.

Leonardo would like to thank all the companies that cooperate as customers and/or supplier in the frame of the above projects that are: TAS France - Cannes, Airbus D\&S UK, SENER and Airbus DS NL.

We also wish to thank the European and Italian Space Agencies for the continuous support in the technology development and AZUR Space for the open minded technical and programmatic collaboration in the frame of the majority of the past and running programs. 